\title{
PORQUE O OKR (OBJECTIVES AND KEY RESULTS) NÃO FUNCIONA EM MINHA EMPRESA
}

\section{ARTIGO ORIGINAL}

DAHER JUNIOR, Elias ${ }^{1}$

DAHER JUNIOR, Elias. Porque o OKR (Objectives and Key Results) não funciona em minha empresa. Revista Científica Multidisciplinar Núcleo do Conhecimento. Ano 05, Ed. 12, Vol. 19, pp. 51-59. Dezembro de 2020. ISSN: 2448-0959, Link de acesso: https://www.nucleodoconhecimento.com.br/tecnologia/minha-empresa

\section{RESUMO}

OKR - Objectives and Key Results é uma metodologia de gestão de métricas que já demonstrou sua efetividade em diversas organizações de classe mundial como Google, Linkedin, Microsoft, Uber e muitas outras: seu principal atributo é o foco ostensivo em resultado e em relevância. Desta forma, consegue medir com extrema facilidade, o progresso em direção aos objetivos estratégicos. Entretanto, nem sempre as implementações alcançam o pleno potencial da ferramenta. Este artigo aborda os principais desafios deste framework, os equívocos que as empresas cometem e o modo para superá-los, com base na Literatura e nos estudos de caso. Não é difícil conhecer a estrutura do OKR, bem como suas melhores práticas. O maior desafio consiste na implementação.

Palavras-Chave: OKR, métricas, indicadores, gestão.

\section{INTRODUÇÃO}

Na década de 1970, a Intel atravessava um período de dificuldades financeiras e o CEO Andy Grove decidiu encerrar a produção de memórias para computador para produzir processadores. Foi uma decisão acertada, porque anos depois, este

\footnotetext{
${ }^{1}$ Economista pela UDF e Analista de Sistemas pela ENAP.
} 
processo instalou computadores em $84 \%$ dos lares americanos. Para conduzir a transição, Grove criou uma metodologia inspirada na MBO (Management by Objectives) de Peter Drucker, que aumentou a receita da empresa de US \$1,9 bilhão para US $\$ 26$ bilhões.

Em sua experiência profissional, o líder da Intel aprendeu a valorizar a execução. Percebeu que o conhecimento sem uma boa implementação produzia resultados medíocres. Para ele, não bastava "parecer ocupado", mas sim, se envolver com os resultados. A revista Time Magazine o elegeu o "Homem do Ano" por ter superado a crise em sua empresa.

Grove era um líder duro. Em 1984 foi eleito um dos chefes mais difíceis dos Estados Unidos, pela revista Hapyness. Lester Hogan afirmou uma vez que se a mãe de Andy Grove atrapalhasse seu planejamento, ele a demitiria. Ainda assim era reconhecido como um dos gestores mais brilhantes do seu tempo. - Nesta época, a truculência no ambiente de trabalho não gerava processos de assédio moral. Depois dele, Steve Jobs, Jeff Bezos ainda repetiram sua fórmula, no entanto, nos dias de hoje, as novas gerações não demonstram disposição para tolerar esse tipo de tratamento. A configuração mais atual do OKR não deve promover o estresse nas equipes sob pena de não conseguir extrair delas, seu melhor potencial (WODTKE, 2014).

Mesmo com a eficácia reconhecida no ambiente da Intel, o OKR permaneceu incógnito até que John Doerr conseguiu vender a ideia para o Google, à época com 40 funcionários. A explosão mundial ocorreu quando Larry Page deu uma entrevista, atribuindo o crescimento de sua empresa, ao uso do framework. Este fato atraiu atenção para o Framework, que se tornou conhecido, utilizado e admirado em todo o mundo.

No modelo original, Drucker sustentava que o que não pode ser medido, não pode ser administrado. Para Grove, o que o indivíduo sabe tem pouco valor: o importante é como ele aplica o seu conhecimento. John Doerr, que presenciou a revolução na Intel, publicou: Ideias não são nada. Implementação é tudo. (DOERR, 2019). 
Figura 1. Linha do tempo do OKR

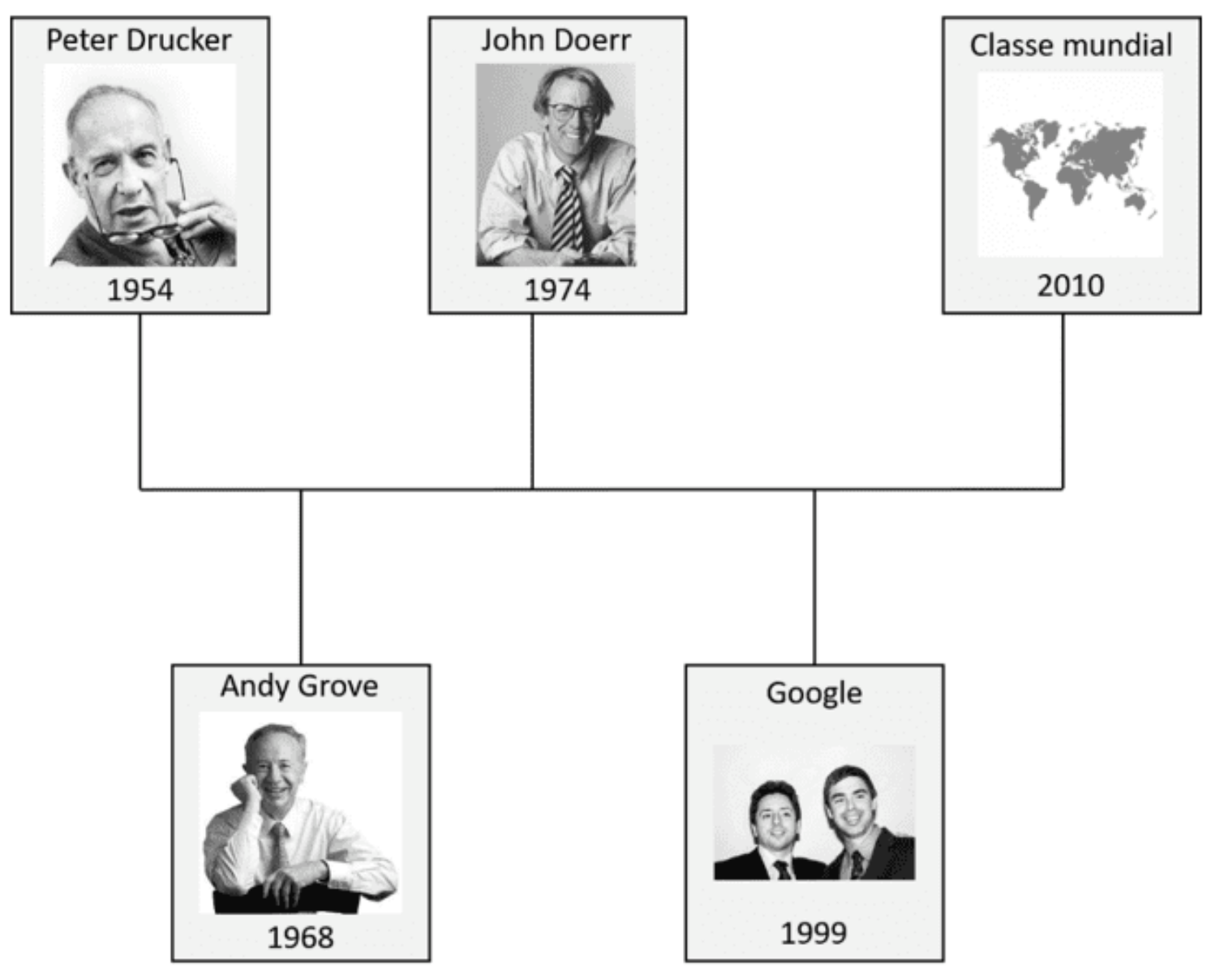

Fonte: O autor

\subsection{ESSÊNCIA DO FRAMEWORK}

OKR é a sigla para Objectives and Key Results. Objetivos indicam uma direção, onde se pretende chegar. Key Results ou resultados-chave representam uma forma de medir a jornada e as Iniciativas representam o que deve ser feito.

Figura 1: Composição do Framework OKR

\section{Objetivo}

Resultados-Chave

Iniciativas 


\begin{tabular}{|l|lrl|l|}
\hline Deve responder à & Medem & o progresso em & Representam as ações \\
pergunta: & direção & ao & objetivo & rotineiras \\
O que queremos? & $*$ & Estamos & atingindo & (o que é preciso fazer para \\
& $*$ Não estamos atingindo & atingir o objetivo)
\end{tabular}

Fonte: o autor

\subsection{POR QUE UTILIZAR O OKR E NÃO OS KPIS TRADICIONAIS?}

Os indicadores comuns normalmente, possuem o ciclo de um ano, quando se avalia ao final do período, o resultado daquela métrica, quando não tem mais o que fazer, somente saber se alcançou ou não. OKR's possuem ciclos mais curtos e exigem avaliações parciais, para que se possa corrigir a estratégia de forma precoce.

Outro problema bastante comum nas organizações é que parte dos colaboradores desconhece os objetivos estratégicos. Desta forma, não se pode mobilizar a empresa para atuar nesta direção. O mesmo ocorre quando os objetivos não são suficientemente claros: se não compreendem, não podem se comprometer com ele. Um objetivo deve ser simples, claro e conter apenas o que se pretende alcançar: nem mais, nem menos. (DOERR, 2019)

Quando os departamentos internos funcionam como silos isolados, fica difícil a fluidez de processos entre eles. Ex.: uma aquisição patrimonial envolve o autor do pedido, a área técnica, o setor jurídico, a Tl e a equipe de compras. É comum encontrar gargalos capazes de atrasar o funcionamento da organização. OKR atua diretamente na colaboração porque sugere a criação de grupos de trabalho com pelo menos um integrante de cada setor envolvido. As decisões se tornam mais céleres, uma vez que todos têm real interesse no sucesso do projeto (DAHER, 2019).

Tanto o KPI quanto o OKR propõem metas ousadas (Nem muito fáceis, nem difíceis demais). A metodologia OKR desafia cada colaborador, do contrário, não se obtém crescimento. No máximo, a manutenção do cenário vigente. (GROVE, 1995). 


\section{DESENVOLVIMENTO}

Uma implementação bem sucedida de OKR não começa com o framework em si, mas com a prévia análise do ambiente, o levantamento dos problemas que se pretende resolver, a avaliação de riscos, o que nem sempre acontece. Existem metodologias que simplificam o processo, aumentando as chances de êxito:

\subsection{GESTÃO DA MUDANÇA}

Toda inovação possui forças que a impulsionam e as forças contrárias. A mudança só ocorre quando as forças propulsoras forem maiores do que as restritivas.

Figura 2. Forças propulsoras $\mathrm{x}$ forças restritivas

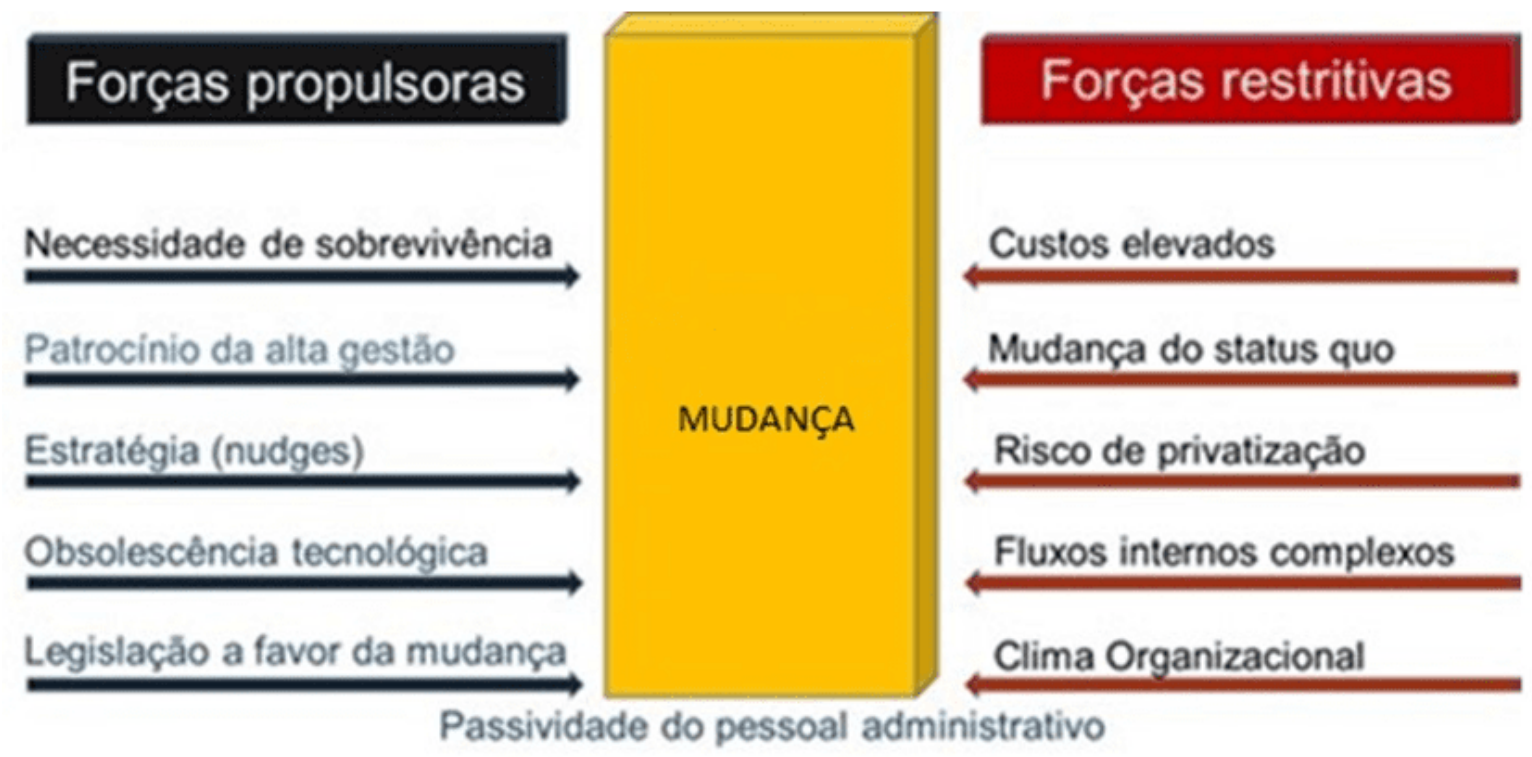

Fonte: o autor

Há determinadas mudanças que são urgentes para a organização, que garantirão sua sobrevivência no mercado. Nesse caso, não se trata de uma opção e os colaboradores precisam estar cientes disso. Outras representam uma reação precoce para se preparar diante das tendências do mercado. Dito isso, compreendemos que a mudança precisa de uma justificativa (LEWIN, 1970). 
Kurt Lewin criou uma metodologia para gerir a mudança: se você tem um grande cubo de gelo, mas o que realmente deseja é um cone de gelo, o que deve fazer? Primeiro derreter o gelo para poder mudar o formato (descongelar). Aí, então, você pode tratar a água gelada da forma que você deseja (mudar). Finalmente, você deve solidificar a nova forma (recongelar). Na prática, eliminar as estruturas vigentes, remodelar e formalizar as novas regras (manuais).

\subsection{POR QUE MEDIR?}

Indicadores existem para acompanhar algum tipo de desempenho ou performance. $\mathrm{O}$ problema é que, quando mal escritos, produzem a falsa impressão de "missão cumprida". Por exemplo, um objetivo estratégico irrelevante mobiliza a empresa inteira em atividades sem potencial de agregar valor. O processo de criação de metas é demorado e no caso do OKR, exige que seja participativo.

Exemplos:

Metas nocivas: Uma empresa de logística recebe reclamações sobre atrasos nas encomendas e decide criar metas para reduzir o tempo de entrega. Para atender esta exigência, os colaboradores podem reduzir os controles de segurança, atuando mais rápido, mas criando um outro problema (mais grave), que é o desvio de mercadorias. Ao estabelecer metas, é preciso incluir alguma que garanta a qualidade e a satisfação do cliente final (DOERR, 2019).

Metas de vaidade: Obter aumento de acessos às plataformas digitais, número de likes e downloads, não representam, necessariamente, engajamento. Para refletir algum crescimento, as métricas precisam demonstrar aumento nas vendas, redução de custos, expansão da área comercial ou fidelização de clientes.

\section{METODOLOGIA}

Por definição, o OKR é uma ferramenta colaborativa de gestão de métricas. Inicialmente o CEO estabelece as metas estratégicas, e as aprova juntamente com a alta direção, que por sua vez, elaboram seus OKR's táticos, com base nos 
estratégicos. Por fim, os líderes intermediários convocam suas equipes para definir os OKR's operacionais (elaboradas pelos funcionários e validadas pelos gerentes). Aqui é preciso ter cuidado, pois não se pode esperar que todos estes atores tenham conhecimento suficiente para criar metas relevantes. É necessário ter profissionais capazes de orientar e questionar os OKR's produzidos (OKR Coaches).

É consenso que os objetivos precisam ser claros para que todos os compreendam. Precisam ser inspiradores para que possam obter engajamento. As métricas selecionadas precisam ser capazes de medir o progresso em direção ao objetivo. OKR é uma metodologia que exige transparência. É necessário promover a divulgação e manter a disponibilidade permanente: tanto dos objetivos, como do progresso.

A personalidade colaborativa do OKR prevê que $60 \%$ das metas sejam definidas no modelo Bottom Up, e não é por acaso. É difícil supor que os líderes possam conhecer mais do chão de fábrica do que a própria força operacional, que vive o dia a dia. Mas muitos não abrem mão dessa hierarquia herdada do fordismo e do taylorismo.

Cada OKR exige um responsável na organização. Não para responder pelo resultado, mas sim, para acompanhar sua evolução, agendar reuniões e refletir com os envolvidos, a partir da experiência, cuidar para que os insumos que os OKR's precisam, sejam fornecidos entre as áreas da empresa. Indicadores tradicionais raramente possuem um responsável. É algo que qualquer um pode fazer, mas ninguém faz.

O maior equívoco que os profissionais cometem com o OKR é definir tarefas do dia a dia como Key Results. Por exemplo, quando se estabelece como "meta", treinar 20 pessoas, ao final 20 colaboradores foram capacitados, não significa necessariamente que houve progresso em direção ao objetivo. Um Resultado chave não depende 100\% do profissional, representa uma hipótese, que pode ser confirmada ou não. Atividades rotineiras dependem só do funcionário. Por esta razão, muitos usam tal artifício, para criar uma falsa sensação de missão cumprida. 
Inobservância da cultura é outro desafio para programas de inovação. Peter Drucker dizia que a cultura devora a estratégia no café da manhã. Isso significa que o melhor planejamento pode sucumbir se não considerar as especificidades internas, que foram consolidadas no decorrer dos anos.

Falta de especialistas: Muitas organizações mobilizam suas equipes internas, sem observar se há reais especialistas entre eles. Normalmente os técnicos fazem pesquisas na internet e se consideram aptos à realização daquela tarefa. Um Framework como o OKR exige profissionais com experiência (Ex.: o OKR Coach, responsável pela relevância de todos os OKR's da empresa. Se este profissional falhar, todo o esforço estará comprometido).

Objetivos mal definidos: movimentam pessoas, tempo e recursos para atingir um patamar, que não agrega valor. Por essa razão é que os ciclos de apuração e revisão do OKR são mais curtos, para que a organização possa corrigir sua estratégia em tempo hábil.

OKR estimula uma cultura do erro, desde que haja aprendizado e com o devido controle de suas dimensões e consequências. Não se pode exigir inovação, crescimento ou resultado sem admitir a possibilidade de erro. Dificilmente os profissionais conseguem acertar na primeira tentativa. Para a metodologia, execução é mais importante do que a ideia. Dá para perceber que OKR é menos papel e mais ação. Menos apego aos processos e mais preocupação com resultados (DOERR, 2019).

\section{CONCLUSÃO}

Apesar da simplicidade da ferramenta, alguns requisitos são críticos e não devem ser negligenciados, como é o caso da presença do OKR Coach para assegurar a relevância dos objetivos e resultados-chave em todos os níveis da organização.

A melhor escola do Framework é o dia a dia nas organizações, quando os profissionais aprendem o que funciona e o que não funciona naquele ambiente. Por esta razão, os 
estudos de caso constituem mera referência. OKR é flexível o suficiente para se ajustar às diferentes realidades nas empresas.

Os primeiros OKRs serão naturalmente frágeis, por esta razão é que se recomenda começar em um setor da organização (projeto piloto), para escalonar em outras áreas conforme o programa alcança maturidade.

O envolvimento das equipes é necessário: em primeiro lugar para contar com a vivência do que acontece no chão de fábrica, e, porque esse tipo de valorização promove engajamento, fundamental para o sucesso do OKR.

OKR não é uma revolução. Da mesma forma que a Transformação Digital, deve fornecer inserções suaves e frequentes. Deste modo suave, quando os colaboradores perceberem, já estarão navegando nas águas da inovação.

Com isso, a jornada estará mais para a técnica e menos para a percepção. Orientada à resultados e não a tarefas.

\section{REFERÊNCIAS}

DAHER, E. Transformação Digital e o futuro do emprego. São Paulo: Clube de Autores, 2019. 207 p.

DOERR, J. Avalie o que importa. Rio de Janeiro: Alta Books, 2019. 305 p.

GROVE, A. Gestão de alta performance. São Paulo: Futura, 1995, 280 p.

KAHNEMAN, D. Rápido e devagar. Rio de janeiro: Objetiva, 2012, 607 p.

LEWIN, K. Field Theory in Social Science. Westport: Greenwood Pub Group. 1970. $436 \mathrm{p}$.

LEWIN, K. Frontiers in group dynamics. New York: Tavistock Institute of Human Relations, 1947, $48 \mathrm{p}$. 
THALER, R. Misbehaving, Rio de Janeiro: Intrínseca, 2019. 447 p.

WODTKE, C. Radical Focus. Califórnia: Cucina Média, 2014. 160 p.

Enviado: Setembro, 2020.

Aprovado: Dezembro, 2020. 